\section{"Bioética Clínica", de Juan Pablo Beca y Carmen Astete (Editores)}

\section{Editorial Mediterráneo, Ltda., Santiago de Chile, 2012 (595 págs) \\ ISBN: 978-956-220-347-0}

Durante mis estudios en la Facultad de Medicina de la Universidad de Chile, la ética médica no se enseñaba en cursos formales, solamente participábamos en seminarios y reuniones clínicas para discutir temas muy especiales, como el aborto y sus consecuencias. Sin embargo, nuestros maestros nos enseñaron con su ejemplo una tradición cultural ética que se forjó antes de que existiera la profesión médica como hoy la concebimos. La confidencialidad, el respeto a la privacidad, el no obtener beneficios pecuniarios desmedidos en la atención de los pacientes, y no dañarlos conscientemente, son conceptos éticos que al parecer nacieron antes de Hipócrates y sus discípulos, cuando los "sanadores", "curanderos" o "chamanes" atendían a seres desvalidos, sufrientes, y respetaban su condición de tales.

Actualmente, la atención de salud y sus proyecciones futuras hacen indispensable y perentorio que la bioética clínica se incorpore no solo a los currículos de pre y postgrado de las Facultades de Medicina, sino también a la actividad profesional de todos quienes velamos por la salud de las personas. Al estudio de estos temas y su práctica consiguiente se han integrado los profesionales de la salud y de otras áreas del saber: filósofos, religiosos, sociólogos, abogados, ingenieros, economistas, administradores que organizan y dirigen las instituciones prestadoras de salud, los legisladores y políticos que asumen responsabilidades en salud, y representantes de la colectividad. La bioética clínica es ahora una especialidad en sí misma, con cultores que han demarcado fronteras del saber cada vez más amplias y doctas, con metodología y normativas precisas.

$\mathrm{Al}$ comenzar a leer este libro me hice la pregunta ¿Por qué se necesita dar tal relevancia a la bioética clínica, llegando a un volumen de casi seiscientas páginas, cuando esta es una materia que hace pocas décadas no se enseñaba formalmente?

La respuesta que puede dar un clínico con más de cincuenta años de actividad profesional, nace de la vertiginosa evolución científica y tecnológica que han experimentado la biología, la psicología y la sociología, y su repercusión en la salud humana. Ello conlleva la aplicación de técnicas altamente eficaces, pero también complejas y peligrosas.

Ya es una observación repetida que el progreso de la medicina ha conducido a la subespecialización precoz de los médicos, que se encasillan en sectores muy restringidos del quehacer profesional. La pérdida progresiva del paternalismo va acompañada por una disminución de la confianza que antaño estaba implícita en la relación de un médico con su paciente. El fácil acceso del público a información médica, muchas veces de dudosa calidad, ha conducido a un aumento de sus expectativas y a exigencias desmedidas. La limitación del tiempo destinado a las acciones profesionales, sean de medicina clínica, de enfermería, de odontología, disminuyen la fidelidad ancestral de los pacientes generando una desconfianza que es un factor crucial en el descrédito de las acciones médicas y en la menor adhesividad de los pacientes a las indicaciones de los profesionales. El respeto a la autonomía del paciente, guiándolo a que sea él, o ella, quien tome una "decisión informada", se convierte muchas veces en una tortura: decidir lo que elegiré que hagan conmigo, o con mi hija, no es lo mismo que decidirnos a comprar una casa, cambiar el automóvil, realizar un viaje o la emigración de una familia. Las decisiones clínicas conjuntas y consensuadas del modelo deliberativo suelen estar dificultadas por el temor o la ansiedad de los pacientes. Los errores médicos ya no se aceptan con la mansedumbre que conocimos hasta hace pocas décadas: ahora provocan rencor, ansias de reparaciones y de castigos, acogidos patéticamente en el ámbito de la judicialización de la medicina.

Así es como un médico comprende que se haya constituido la bioética clínica en una guía fundamental para el ejercicio profesional y la docencia. Una frase en la página 203 de este texto podría sintetizar el rol de la bioética clínica, cuando pretende ayudar a cumplir la premisa de "cuidar de la salud de las personas respetándolas como tales".

Si ese fue el propósito de este texto, sea bienvenido. Ahora, analicemos cómo lo enfrentaron sus editores, considerando que el libro -y cito frases de la Introducción- "está destinado a todos los profesionales de la salud que buscan un continuo perfeccionamiento en su actividad profesional y persiguen profundizar su vocación, a docentes de carreras en ciencias de la salud, a estudiantes de universidades hispanoamericanas, a los miembros 
de los Comités de Ética Asistencial, a quienes trabajan dando apoyo espiritual a los pacientes y a alumnos de carreras humanistas y científicas llamados a participar en la reflexión sobre los fundamentos éticos de esta disciplina y mejorar las prácticas bioéticas en la sociedad."

Cuarenta y siete personas intervinieron como autores de capítulos. Una buena proporción de ellos son docentes de seis universidades chilenas, agregándose especialistas de España, Estados Unidos de Norteamérica, Puerto Rico, Colombia, Venezuela y Uruguay, todos pertenecientes a prestigiadas universidades y centros académicos. Los temas tratados se agruparon en cinco partes: Conceptos fundamentales, Bioética en la práctica clínica, en el inicio de la vida, en el final de la vida, y en otras profesiones de la salud, como Enfermería y Odontología.

Los editores lograron cumplir una finalidad ambicionada para todo libro con multiautoría, cual es conseguir un texto fluido, armónico, en que el lector pasa de un capítulo al siguiente sin notar que el autor es otro. Aquí no hay divagaciones que no culminen en un propósito práctico. Los autores exponen su tema, lo comentan, proponen conclusiones y hacen recomendaciones, o sea analizan qué es, por qué es y qué deberíamos hacer. La mirada al futuro está presente en cada capítulo de este interesante libro.

Si ejercemos nuestra profesión con autenticidad y experiencia clínica, tenemos que reconocer que dos condiciones inherentes a la medicina son la responsabilidad y la incertidumbre. Ningún texto de medicina va a resolver todos nuestros problemas, pero "Bioética Clínica" de Beca y Astete, será, a mi entender y por mucho tiempo, un referente indispensable para que respetemos y hagamos respetar las condiciones con que tenemos que enfrentar nuestras responsabilidades y nuestras incertidumbres.

Dr. Humberto Reyes B. Profesor Emérito, Universidad de Chile. Miembro de Número, Academia Chilena de Medicina. 